\title{
Juventude e poder local: um balanço de iniciativas públicas voltadas para jovens em municípios de regiões metropolitanas
}

\author{
Marilia Pontes Sposito \\ Universidade de São Paulo, Faculdade de Educação \\ Programa de Pós-Graduação em Educação
}

\section{Hamilton Harley de Carvalho e Silva}

Universidade de São Paulo, Faculdade de Educação

Bolsista de Capacitação Técnica/FAPESP

\section{Nilson Alves de Souza}

Universidade de São Paulo, Faculdade de Educação,

Bolsista de Iniciação Científica/CNPq

\section{Introdução}

Quando propusemos a investigação em torno das ações destinadas aos jovens em 74 prefeituras de cidades brasileiras, algumas inquietações ancoravam a pesquisa a ser empreendida. ${ }^{1}$ Considerávamos que as políticas e ações destinadas aos jovens podem ser também investigadas a partir do modo peculiar como constroem uma imagem do ciclo de vida e seus sujeitos. Inspirados em Lagree (1999), tomávamos como hipótese preliminar de investigação a idéia de que há uma interconexão entre aquilo que tende a se tornar uma representação normativa corrente da idade e dos jovens na sociedade e o próprio impacto das ações políticas na esfera pública. Dito de outra forma, a conformação das políticas e programas públicos não sofre apenas os efeitos de concepções, mas pode provo-

1 Trata-se do Projeto Juventude, Escolarização e Poder Local, desenvolvido com o apoio da Fundação de Amparo à Pesquisa do Estado de São Paulo (FAPESP) e do Conselho Nacional de Desenvolvimento Científico e Tecnológico (CNPq), em 2003-2006. car modulações nas imagens dominantes que a sociedade constrói sobre seus sujeitos jovens.

A decisão de tomar como base empírica os executivos municipais decorreu da reconhecida importância da gestão municipal no processo de democratização da sociedade brasileira, a partir da década de $1980 .^{2}$ O poder municipal tornou-se campo privilegiado de análise porque nele as relações entre sociedade civil e Estado, para a conformação de uma esfera pública democrática, aparecem de forma mais clara e oferecem focos importantes para a realização de pesquisas. ${ }^{3}$ Tanto os aspectos inovadores e democráticos

2 Não considerávamos apenas alguns efeitos inovadores no âmbito da descentralização e da reforma do Estado, já analisados por outros autores como Pereira, Wilheim e Sola (1999) e Draibe (1998).

3 Foge do escopo deste artigo recuperar toda a discussão em torno dos conceitos de sociedade civil e esfera pública observada nas ciências sociais no Brasil. Para os efeitos da análise aqui empreendida, vale reiterar que o conceito de sociedade civil adquire maior visibilidade sobretudo com o processo de democrati- 
como as reiterações de práticas incrustadas em uma cultura política do mandonismo local estavam no universo de preocupações, pois a diversidade de modos de constituição da ação governamental e da esfera pública nas cidades é ampla e evidente.

Os 74 municípios pesquisados retratam um caleidoscópio rico de possibilidades de compreensão da dinâmica sociopolítica local, uma vez que estão situados em regiões metropolitanas diversas (Tabela 1). $\mathrm{Na}$ Região Sul, investigamos a Região Metropolitana de Porto Alegre e Florianópolis; no Sudeste, privilegiamos oito municípios da Região Metropolitana de São Paulo e constituímos o ABC e seus municípios como uma unidade específica de análise. ${ }^{4}$ Incorporamos as Regiões Metropolitanas do Rio de Janeiro, Belo Horizonte e Vitória; no Nordeste, a Região Metropolitana de Recife foi pesquisada, e no CentroOeste foi selecionada a recém-criada Região Metropolitana de Goiânia.

No universo de investigação estão compreendidos cerca de oito milhões de jovens entre 15 e 24 anos, para uma população total de aproximadamente quarenta milhões de habitantes. Os municípios escolhidos não responderam aos critérios de uma amostra probabilística, mas certamente o conjunto das informações não deixa de oferecer um quadro bastante representativo das ações municipais de regiões metro-

zação (Pereira, Wilheim \& Sola, 1999; Draibe, 1998). Sola (1998) considera que, não obstante a diversidade dos modos de abordagem, há pontos de forte convergência entre os autores, quando examinam a cultura política, os valores e os desenhos institucionais como elementos importantes a conformar a sociedade civil em uma perspectiva democrática.

4 Apesar de integrar a região metropolitana da cidade de São Paulo, os municípios que compõem o ABC - São Bernardo, Santo André, São Caetano, Diadema, Mauá, Ribeirão Pires e Rio Grande da Serra - constituem uma unidade específica, tanto do ponto de vista econômico, por tratar-se do local onde foi implantada a indústria automobilística brasileira, como do ponto de vista político, pois o novo sindicalismo e o Partido dos Trabalhadores tiveram origem nessa região. politanas brasileiras que têm como alvo os segmentos juvenis. ${ }^{5}$

Tabela 1 - Municípios estudados por região metropolitana

\begin{tabular}{|c|c|c|}
\hline Região & Município & $\begin{array}{c}\text { População } \\
\text { total }\end{array}$ \\
\hline $\begin{array}{l}\text { SP } \\
13\end{array}$ & $\begin{array}{l}\text { Embu, Guarulhos, Jandira, Mogi das } \\
\text { Cruzes, Osasco, São Paulo, Diadema, } \\
\text { Mauá, Ribeirão Pires, Rio Grande da } \\
\text { Serra, Santo André, São Bernardo, } \\
\text { São Caetano }\end{array}$ & 15.143 .995 \\
\hline $\begin{array}{c}\text { SC } \\
4\end{array}$ & $\begin{array}{l}\text { Biguaçu, Florianópolis, Palhoça, São } \\
\text { José }\end{array}$ & 666.675 \\
\hline $\begin{array}{c}\text { ES } \\
6\end{array}$ & $\begin{array}{l}\text { Cariacica, Guarapari, Serra, Viana, } \\
\text { Vila Velha, Vitória }\end{array}$ & 1.425 .587 \\
\hline $\begin{array}{l}\text { RJ } \\
20\end{array}$ & $\begin{array}{l}\text { Belford Roxo, Duque de Caxias, } \\
\text { Guapimirim, Itaboraí, Itaguaí, Japeri, } \\
\text { Magé, Mangaratiba, Maricá, } \\
\text { Mesquita, Nilópolis, Niterói, Nova } \\
\text { Iguaçu, Paracambi, Queimados, Rio } \\
\text { de Janeiro, São Gonçalo, São João } \\
\text { de Meriti, Seropédica, Tanguá }\end{array}$ & 10.894 .156 \\
\hline $\begin{array}{c}\mathrm{GO} \\
4\end{array}$ & $\begin{array}{l}\text { Aparecida de Goiânia, Goiânia, } \\
\text { Senador Canedo, Trindade }\end{array}$ & 1.563 .961 \\
\hline $\begin{array}{c}\text { MG } \\
12\end{array}$ & $\begin{array}{l}\text { Belo Horizonte, Betim, Caeté, } \\
\text { Contagem, Ibirité, Lagoa Santa, } \\
\text { Nova Lima, Ribeirão das Neves, } \\
\text { Sabará, Santa Luzia, Sete Lagoas }\end{array}$ & 4.163 .654 \\
\hline $\begin{array}{l}\text { RS } \\
11\end{array}$ & $\begin{array}{l}\text { Alvorada, Cachoeirinha, Canoas, } \\
\text { Esteio, Gravataí, Guaíba, Novo } \\
\text { Hamburgo, Porto Alegre, São } \\
\text { Leopoldo, Sapucaia do Sul, Viamão }\end{array}$ & 3.145 .119 \\
\hline $\begin{array}{c}\text { PE } \\
4\end{array}$ & $\begin{array}{l}\text { Cabo de Santo Agostinho, } \\
\text { Camaragibe, Olinda, Recife }\end{array}$ & 2.072 .486 \\
\hline Total & 74 & 39.075 .633 \\
\hline
\end{tabular}

Fonte: IBGE (2000).

5 A juventude rural de modo geral e os jovens residentes em pequenos municípios brasileiros são realidades pouco investigadas no âmbito dos estudos sobre juventude no Brasil e não estão contemplados nesta pesquisa. 
O espectro foi amplo não só do ponto de vista sociodemográfico, compreendendo pequenos, médios e grandes municípios e todas as capitais, como pela ótica do arco de alianças e partidos no poder, igualmente diversificado (Tabela 2). De modo geral, administrações do Partido dos Trabalhadores (PT) ou produtos de coalizão de frentes partidárias mais à esquerda têm constituído o campo mais intenso das ações para a juventude. ${ }^{6}$ No entanto, é preciso considerar que há diferenças substantivas no interior de prefeituras administradas por um mesmo partido, indicando que as práticas locais, as forças políticas e os principais atores envolvidos conformam significativa diversidade no delineamento e nos pressupostos das iniciativas. A heterogeneidade ocorre, também, no âmbito dos diferentes ritmos de consolidação ou implementação das ações voltadas para o segmento juvenil, mas em geral todas são muito recentes, tendo sido iniciadas em meados dos anos de 1990.

Tabela 2 - Distribuição dos partidos nos municípios investigados

\begin{tabular}{|l|c|c|}
\hline Partidos & $\begin{array}{c}\text { Número de } \\
\text { políticos }\end{array}$ & $\begin{array}{c}\text { Número de } \\
\text { prefeituras em 2001 }\end{array}$ \\
prefeituras em 2005
\end{tabular}

6 Informalmente, muitos gestores declararam que o primeiro partido a empreender ações e a defender bandeiras junto aos jovens foi o Partido Comunista do Brasil (PCdoB), sobretudo a Juventude Socialista. No entanto, gradativamente, essas orientações atingiram as hostes jovens do PT e, com menor intensidade, a juventude do Partido da Social Democracia Brasileira (PSDB).
$\mathrm{O}$ instrumento que orientou a coleta de dados foi aplicado junto aos coordenadores das iniciativas, ${ }^{7}$ e o número total registrado (796) constitui um universo importante de dados empíricos a serem trabalhados. As informações sistematizadas decorrem do modo como o responsável pela ação vislumbra seus objetivos, suas características e seu impacto. Exprimem de algum modo as suas concepções normativas sobre os jovens e as possibilidades de participação desses segmentos na definição de uma agenda pública no âmbito do município. Em geral, os informantes são gestores situados nos escalões intermediários, subordinados ao titulares das pastas. Alguns são coordenadores de órgãos especialmente criados para a implantação de ações - as assessorias e coordenadorias de juventude -, respondendo diretamente ao gabinete do prefeito ou a alguma secretaria de governo. As percepções e informações cruzam, assim, diferentes idades, uma vez que os informantes podem ser eles mesmos jovens, alocados na máquina pública do executivo municipal. Embora o quadro apresentado reúna informações valiosas, é importante ressaltar que exprime o grau de conhecimento e a percepção que o informante detém do programa/projeto sob sua responsabilidade. Essa constatação é essencial, pois um estudo exaustivo das políticas envolveria, em cada um dos municípios, entrevistas com os vários escalões responsáveis, incluindo o acompanhamento das ações no seu cotidiano. As observações e análises aqui contempladas constituem um primeiro esforço em torno de alguns temas abordados pelo instrumento e não esgotam todo o universo temático compreendido pela pesquisa.

7 As ações referidas neste texto contemplam modalidades diversas de intervenção do Executivo municipal. Elas tanto podem ser episódicas, na forma de eventos ou campanhas, como podem derivar de projetos que definem de modo sistematizado os objetivos e as atividades propostas, ou de programas que configuram atividades planejadas para atingir metas de caráter mais duradouro. No entanto, para efeitos de redação, não será feita distinção entre eles, que poderão ser utilizados como sinônimos. O formulário aplicado compreendia 58 questões e quatro perguntas de natureza qualitativa. 


\section{O emergente campo das ações: algumas reiterações e tendências}

Ao analisarmos as políticas federais voltadas para a juventude, verificamos em artigo anterior (Sposito \& Carrano, 2003) que a emergência das ações federais ocorreu na segunda gestão do governo Fernando Henrique Cardoso, sobretudo a partir de 1997. Nesse momento, foi intensa a repercussão pública do assassinato do índio Galdino por jovens de camadas médias, e a associação entre juventude e violência fezse mais forte. Mas é preciso considerar, também, que o clima decorrente das rebeliões de jovens em conflito com a lei nas dependências de várias unidades estaduais da Fundação Estadual do Bem-Estar do Menor (FEBEM) aparece largamente retratado pela imprensa a partir de meados da década de 1990, induzindo a uma visibilidade perversa de vários segmentos de adolescentes pobres (Sales, 2005).

Esse clima dominante de percepções em torno da articulação entre juventude pobre e violência, agravado pela disseminação de tais práticas nas classes médias, provavelmente influenciou os municípios de modo geral, pois a maioria das ações, conforme os dados da Tabela 3 indicam, tem início a partir de 1997. No período entre 1997 e 2000 verifica-se a expansão dos programas (21\%), acentuada significativamente no último período (entre 2001 e 2004), que reúne $64,8 \%$ das iniciativas. As duas últimas gestões municipais são, assim, responsáveis por quase $86 \%$ das ações. No momento do trabalho de campo, os programas, em sua maioria, encontravam-se em fase de implementação, representando um percentual de $72,4 \%$ contra somente $8,4 \%$ dos considerados encerrados, como pode ser observado na Tabela $4 .{ }^{8}$

Chama atenção a pouca efetividade dos dispositivos previstos pelo Estatuto da Criança e do Adolescente (ECA) no âmbito do Executivo municipal, logo após sua promulgação. Duas possibilidades podem ser

8 O trabalho de levantamento dos dados foi realizado durante o ano de 2003 e finalizado em fevereiro de 2004. aventadas para essa ausência de políticas no interior de governos municipais a partir da vigência do ECA: a primeira reside na hipótese de uma ausência de iniciativas, pois a luta efetiva pelos direitos não repercute na esfera municipal, que se volta para a questão apenas no final da década de 1990; a segunda, mais otimista, incide sobre a possibilidade de terem sido implantadas algumas ações de curta duração, sofrendo a descontinuidade habitual das políticas públicas no país. ${ }^{9}$

Tabela 3 - Ano de início do projeto

\begin{tabular}{|l|c|c|}
\hline Períodos & Quantidade & $\%$ \\
\hline Até 1980 & 5 & 0,6 \\
$1981-1984$ & 3 & 0,3 \\
$1985-1988$ & 6 & 0,8 \\
$1989-1992$ & 18 & 2,3 \\
$1993-1996$ & 39 & 4,9 \\
$1997-2000$ & 166 & 20,9 \\
$2001-2004$ & 516 & 64,8 \\
Não informado & 43 & 5,4 \\
\hline Total & 796 & 100 \\
\hline
\end{tabular}

Tabela 4 - Fase atual do programa/projeto

\begin{tabular}{|l|r|r|}
\hline Fase atual & Freqüência+ & $\%$ \\
\hline do programa & & \\
Concepção & 43 & 5,4 \\
Implementação & 576 & 72,4 \\
Avaliação & 48 & 6,0 \\
Programa encerrado & 67 & 8,4 \\
Não executado & 9 & 1,1 \\
Não respondido & 53 & 6,7 \\
\hline Total & 796 & 100,0 \\
\hline
\end{tabular}

De certo modo, obedecendo à trajetória das políticas públicas em nível federal para a juventude no

9 Se o ECA abriu possibilidades para a constituição de uma nova concepção de infância ou de desenhos institucionais mais avançados por meio da constituição dos conselhos, impulsionando ações no Judiciário (promotorias, varas da infância, medidas em relação a adolescentes em conflito com a lei), não há avaliações ou estudos disponíveis do ponto de vista de sua efetivação no interior das políticas do Poder Executivo nos três níveis da federação brasileira. 
Brasil, os dados obtidos revelam que os organismos responsáveis ${ }^{10}$ pelo maior número de programas levantados são as secretarias ligadas à assistência social/inclusão/ação social, com $23 \%$ de citações, seguidas pela secretarias de educação, que concentram $16,2 \%$ das ações destinadas a essa faixa da população. Em terceiro lugar aparecem as secretarias municipais de cultura (12,2\%), com índices bem próximos à área de esportes. Além disso, podemos observar que outras secretarias municipais contemplam iniciativas na forma de projetos ou programas para a juventude de modo mais esparso. Esses dados, apesar de não serem numericamente muito expressivos, revelam que ocorre uma crescente abertura da temática juventude na agenda política dos governos municipais, incluindo novas áreas como habitação, turismo, segurança pública e cidadania, somando $11,7 \%$ das iniciativas. Embora seja crescente o número de organismos envolvidos nas ações do Executivo municipal, ainda não se observa com a mesma intensidade uma contrapartida institucional capaz de articular essas ações. As coordenadorias e secretarias municipais de juventude - produto de novos desenhos institucionais - agregam apenas $6,9 \%$ das ações destinadas a essa faixa da população, evidenciando seu caráter emergente no desenho das políticas (Tabela 5).

Mas é importante reconhecer que essa porosidade revelada pela pesquisa indica, também, um traço reiterativo das políticas públicas no país: dispersão, fragmentação e superposição, como afirmou Rua (1998).

Em contrapartida, a predominância da área da assistência social leva-nos a considerar que as políticas de juventude aparecem de forma subsidiária à questão social, sendo considerada um aspecto - por que não dizer menor - dessa grande problemática. Sales (2005), ao examinar o tema dos jovens em conflito com a lei e sua (in)visibilidade perversa, considera que as orientações e políticas derivadas do ECA sempre foram

${ }^{10}$ Os programas/projetos podem estar ligados a mais de uma secretaria, portanto, o total de respostas é maior do que o número de ações. subtemas da questão social e, portanto, com escassa legitimidade para desencadear ações governamentais. No entanto, deve ser questionada não apenas a condição de serem subtemas, mas o próprio fato de inscreverem-se as ações, de modo exclusivo, no âmbito da questão social, mesmo que alcancem em seu interior certa prioridade. Essa inscrição significa dar visibilidade e propor as políticas de juventude sempre subordinadas ao tema da questão social. Não é estranha, portanto, a reiteração das problemáticas da vulnerabilidade, do risco e da violência, como fatores que desencadeiam a ação tanto do Executivo municipal como do federal, a partir de meados dos anos de 1990. Ou seja, as políticas de juventude no país não nascem a partir da constituição de um espaço de visibilidade da condição juvenil moderna, incluindo sua diversidade, e uma concepção ampliada de direitos - os novos regimes de cidadania (Loncle-Moriceau, 2001), mas como um aspecto da questão social. Por essas razões, a inserção das ações de forma predominante no âmbito dos organismos da assistência traduz alguma coerência que dificulta, no entanto, a alteração de imagens que condensam estereótipos negativos em relação aos adolescentes pobres.

Tabela 5 - Número de ações por secretaria municipal

\begin{tabular}{|l|r|r|}
\hline Secretarias municipais* & $\begin{array}{r}\text { Freqüência } \\
\text { absoluta (FA) }\end{array}$ & $\%$ \\
\hline De assistência social/ & & \\
inclusão/ação social & 237 & 23,0 \\
De educação & 167 & 16,2 \\
De saúde & 56 & 5,4 \\
De meio ambiente & 27 & 2,6 \\
Do esporte & 114 & 11,0 \\
Da cultura & 126 & 12,2 \\
De trabalho & 45 & 4,4 \\
De governo & 17 & 1,6 \\
De habitação & 21 & 2,1 \\
De turismo & 35 & 3,4 \\
De juventude & 71 & 6,9 \\
De segurança pública & 7 & 0,7 \\
De participação/cidadania & 58 & 5,6 \\
Outras & 17 & 1,6 \\
Não informado & 34 & 3,3 \\
\hline Total & 1.032 & 100,0 \\
\hline
\end{tabular}

* Múltipla escolha 
A questão social no país, durante a maior parte do século $\mathrm{XX}$, foi tradicionalmente tratada como "questão de polícia". De modo gradativo, a área da assistência social trouxe-a para a esfera dos direitos, lutando por estabelecer um novo recorte e uma compreensão dos processos de exclusão como determinantes da questão social. No entanto, do ponto de vista das políticas de juventude, a visibilidade que ocorre origina-se, sobretudo, dos adolescentes pobres, em situação de rua ou em conflito com a lei. Essa visibilidade, agravada por um clima de insegurança social, engendra demandas de controle e de disciplinamento da conduta desses jovens. Talvez essa seja uma forte razão para a demora na constituição de um discurso público favorável às políticas de juventude, capaz de romper com a associação entre juventude, vulnerabilidade, risco e violência, inserindo-o na esfera dos direitos das múltiplas cidadanias.

Se considerarmos, como Rancière (1996), que a "política", diferentemente da "polícia", é produtora de certo dissenso, na medida em que introduz o litígio, ou seja, a possibilidade de produção de novos significados e de trazer à luz sujeitos que permanecem na sombra e, portanto, não são atingidos pelos pressupostos da igualdade, não podemos, estrito senso, falar de políticas de juventude. ${ }^{11} \mathrm{O}$ emergente espaço das ações ainda se inscreve na lógica de um consenso dominante: as iniciativas públicas devem prevenir ou conter a violência e as condutas de risco de jovens de camadas populares. Defensores dos novos direitos consagrados pelo ECA, atores que na vida pública se dedicam aos adolescentes privados de direitos, ainda são identificados como parte do campo

${ }^{11}$ Para Rancière (1996), a polícia designa a lógica de quantificar e assinalar a população em lugares diferentes enquanto a política alude à subversão dessa lógica diferencial por meio da constituição de um discurso igualitário que põe em julgamento identidades já estabelecidas. Se o debate permaneceu circunscrito ao eixo da violência e de os jovens - mesmo que se denuncie a sua condição de vítimas -, torna-se muito difícil subverter associações estabelecidas. de significados recobertos pela idéia de violência e de vulnerabilidade. Não obstante a busca de criação de um dissenso, uma vez que parte dos atores que atuavam no campo tentou produzir novos significados, a prática limitou-se aos sujeitos que já estavam sendo considerados apenas na sua condição de vulnerabilidade ou de violência potencial. Deixando à sombra outros aspectos dos sujeitos jovens - para além de sua vulnerabilidade -, a lógica dominante prevaleceu, reiterando, mesmo que com outras designações, a dissociação, outrora recoberta pela idéia do "menor". Verifica-se agora a cisão entre adolescentes "vulneráveis ou em situação de risco" e os jovens. Estes últimos começam a ser reconhecidos como sujeitos de direitos - plenos e legitimados pela sociedade -, e os "outros", até recentemente cunhados como "menores", seriam objeto de ações reparadoras ou preventivas de sua provável delinqüência.

Nem mesmo a recente discussão em torno do emprego/desemprego juvenil consegue romper com essa lógica, uma vez que o tema do desemprego aparece associado ao combate ao crime e ao tráfico que "arrebanha” jovens desocupados. O tempo livre juvenil aparece como sintoma de perigo, sobretudo quando está pressuposta a imagem do ócio de sujeitos do sexo masculino, pobres e de origem negra. ${ }^{12}$

A Tabela 6 ilustra algumas dessas hipóteses enunciadas, pois se verifica que a principal área de atividade dos programas está voltada para o acompanhamento e reinserção social, com $20,9 \%$ de respostas apontadas como primeira prioridade em uma hierarquia de citações. Em segundo lugar aparecem os programas vinculados à área de cultura, e nela são majoritárias as propostas de cunho artístico como a dança, o teatro, a música e as artes plásticas, perfazendo um total de $19,2 \%$ das respostas em primeira prioridade.

\footnotetext{
${ }^{12}$ Essas questões são importantes porque constituem políti-
} cas que não consideram o fato de o desemprego afetar mais as jovens do que os jovens (Sposito, 2005). Provavelmente, as mulheres jovens, em virtude das formas de socialização predominantes, não constituem ameaça social. 
O estímulo à participação juvenil como primeira prioridade aparece em apenas $12,9 \%$ das atividades e, se considerarmos três possibilidades, as áreas mais citadas são cultura, inserção social e esportes.

Tabela 6 - Área de atividades dos programas/projetos

\begin{tabular}{|l|r|r|r|r|}
\hline \multirow{2}{*}{ Área de atividade } & \multicolumn{2}{|c|}{$\begin{array}{c}\text { Três áreas mais } \\
\text { importantes }\end{array}$} & \multicolumn{2}{|c|}{$1^{\text {a }}$ opção } \\
\cline { 2 - 5 } & \multicolumn{1}{|c|}{ FA } & \multicolumn{1}{|c|}{ FA } & \multicolumn{1}{c|}{$\%$} \\
\hline Cultura & 489 & 23,4 & 153 & 19,2 \\
Estímulo à participação e & & & & \\
protagonismo juvenil & 227 & 10,9 & 103 & 12,9 \\
Esporte e lazer & 346 & 16,6 & 114 & 14,3 \\
Saúde & 196 & 9,4 & 80 & 10,1 \\
Mundo do trabalho & 174 & 8,3 & 68 & 8,5 \\
Acompanhamento e & & & & \\
reinserção social & 445 & 21,3 & 166 & 20,9 \\
Educação ambiental & 39 & 1,9 & 9 & 1,1 \\
Escolarização & 34 & 1,6 & 24 & 3,0 \\
Produção literária & 12 & 0,6 & 7 & 0,9 \\
Pesquisa & 8 & 0,4 & 6 & 0,8 \\
Atividades religiosas & 9 & 0,4 & 0 & 0,0 \\
Outros & 92 & 4,4 & 49 & 6,2 \\
Não respondido & 17 & 0,8 & 17 & 2,1 \\
\hline Total & 2088 & 100,0 & 796 & 100,0 \\
\hline
\end{tabular}

Se agruparmos alguns dos objetivos das ações, identificados pelos entrevistados, verificamos o seguinte quadro: $13,7 \%$ apresentam metas culturais estrito senso, 9,6\% articulam-se à inserção e inclusão sociais, sem considerarmos ações semelhantes no âmbito do trabalho ou da escola, tendo em vista sua especificidade. São significativos os objetivos voltados para os temas da escola - por que não dizer inclusão escolar? -, reunindo $13,5 \%$ das respostas, e os objetivos ligados ao esporte, incluindo $7,9 \%$ das menções (Tabela 7).

Como a freqüência de respostas em torno de alguns objetivos é maior do que o número de ações envolvidas na mesma modalidade, depreende-se que, para cada modalidade de ação, mais de um objetivo está previsto. No entanto, o número de citações em torno dos objetivos não poderia ser menor do que as modalidades respectivas. Curiosamente, se tomarmos como exemplo a prática esportiva, verificamos que há maior número de citações nas modalidades ofere- cidas (em torno de 14\% das ações) do que nos objetivos (em torno de 8\%). Essa discrepância pode indicar que a prática esportiva aparece como estratégia para a consecução de outros objetivos que não incluem a própria prática do esporte. ${ }^{13}$ As diferenças mais expressivas situam-se no domínio da cultura, incluindo as expressões artísticas. Como primeira opção, as expressões culturais e artísticas são a modalidade principal em quase $20 \%$ dos programas em nível nacional, ao passo que $13 \%$ dos objetivos pretendidos se situam no domínio da cultura. Além disso, cerca de $21 \%$ das ações estão no campo da inserção social, mas os objetivos dessa área limitam-se a 9\%, aproximadamente. Alguns desencontros são importantes de ser assinalados. Parte das ações voltadas para a cultura não apresenta objetivos nessa área, talvez caracterizando a ação cultural, como já observado no esporte, como estratégia para outros fins. Do mesmo modo, muitas ações desenvolvidas na área da inserção social/assistência social contemplam objetivos diversificados.

Um aprofundamento dessas questões incidiria para o reforço de uma hipótese que aponta para o caráter instrumental das práticas - artísticas e esportivas -, que passam a se constituir como porta de entrada para objetivos estranhos ao mundo cultural e dos esportes. Não se trata de negar que práticas culturais e esportivas produzem benefícios amplos para aqueles que a praticam (auto-estima, construção de identidades, possibilidades de agregação e de participação, entre outras). ${ }^{14}$ Outra lógica ocorre quando o objetivo é conter a violência, agressividade, comportamentos ameaçadores e, portanto, utiliza-se a arte ou o esporte

${ }^{13}$ Em contrapartida, no âmbito do esporte há uma clara clivagem entre a prática esportiva que tem como objetivos identificar e promover talentos, mais freqüente nos grandes programas apoiados por empresas, e as práticas de usufruto coletivo e democrático que têm como meta a possibilidade de acesso ao esporte (Martins, 2004).

14 Basta recorrer a Elias (em Elias \& Dunning, 1995) quando analisa os efeitos pacificadores das práticas esportivas. 
para a obtenção de algum benefício de outra ordem, esvaziando-se as metas inerentes à atividade. Quando a prática cultural ou esportiva aparece apenas como um instrumento para outros objetivos, em geral ela pouco agrega em termos de competências específicas, técnicas e materiais necessários. Sempre pode ocorrer um verdadeiro simulacro da expressão artística ou esportiva, disseminando-se projetos com poucos materiais ou recursos, sendo empreendidos por pessoas pouco capacitadas.

Em contrapartida, se de fato as metas de inclusão são menos freqüentes do que as ações consideradas desse tipo, outro tema para a análise pode ser identificado: atividades declaradas como de inclusão social têm objetivos diversos, o que sinaliza um escopo amplo e difuso de metas abrangidas pelas expressões inclusão ou inserção social. Se o discurso da exclusão, como afirma Martins (1997), é impreciso e pode levar a incorreções conceituais com conseqüências políticas perversas, o discurso da inclusão, provavelmente, inscreve-se na mesma chave. ${ }^{15}$

No tema do estímulo à participação juvenil ou protagonismo, há um índice ligeiramente maior de citações nos objetivos do que no de modalidades, o que leva a imaginar que outras práticas (esportivas, culturais, de lazer, de acompanhamento e inserção, complemento escolar etc.) estariam também cumprindo esse tipo de meta. Resta apenas indagar se todas as possibilitam e se, de fato, a participação e o protagonismo estão disseminando-se para outras práticas. Chama a atenção, também, a freqüência de objetivos voltados para a melhoria de condições escolares dos

${ }^{15}$ É muito comum em ações consideradas de inserção social ter como meta central o desenvolvimento da auto-estima. Sem menosprezar a importância dessa característica na vida dos jovens, resta a pergunta: a promoção da auto-estima de fato favorece o acesso dos jovens ao mundo da educação, da cultura, do trabalho e do lazer? Se tratarmos de um conjunto de direitos negados, não seria o fomento da auto-estima daqueles que são privados do acesso a esses bens o mecanismo básico de sua inserção se os direitos continuam negados. jovens e, de modo concomitante, a pouca presença de atividades de complementação à escolaridade. Ao que tudo indica, parte das ações opera com o pressuposto de que um leque grande de atividades desenvolvidas no campo não-escolar - culturais, esportivas, de participação - agiria positivamente na relação dos jovens com a própria escola. Contudo, se grande parte das dificuldades escolares dos jovens decorre das características das práticas educativas oferecidas pelas

Tabela 7 - Objetivos das iniciativas

\begin{tabular}{|c|c|c|}
\hline Objetivos* & FA & $\%$ \\
\hline $\begin{array}{l}\text { Melhoria das condições de freqüência/ } \\
\text { permanência escolar }\end{array}$ & 55 & 4,8 \\
\hline $\begin{array}{l}\text { Proporcionar atividades extra-escolares/ } \\
\text { cursos alternativos a escola }\end{array}$ & 68 & 5,9 \\
\hline Oferecer curso pré-vestibular & 6 & 0,5 \\
\hline Favorecer a inclusão escolar & 24 & 2,1 \\
\hline Trabalhar com diversidade sociocultural & 18 & 1,6 \\
\hline $\begin{array}{l}\text { Ampliar/desenvolver universo cultural/ } \\
\text { artístico dos jovens }\end{array}$ & 139 & 12,1 \\
\hline Complementar renda & 16 & 1,4 \\
\hline Erradicar o trabalho infantil & 22 & 1,9 \\
\hline $\begin{array}{l}\text { Inserir/qualificar no/para o mercado de } \\
\text { trabalho/Preparar para o mercado de } \\
\text { trabalho }\end{array}$ & 91 & 7,9 \\
\hline $\begin{array}{l}\text { Desenvolver consciência ambiental/ } \\
\text { trabalhar com meio ambiente }\end{array}$ & 28 & 2,4 \\
\hline Oferecer atividades esportivas & 91 & 7,9 \\
\hline $\begin{array}{l}\text { Prevenir a violência/oferecer atendimento } \\
\text { psicossocial e educacional às vítimas de } \\
\text { violência e familiares }\end{array}$ & 41 & 3,6 \\
\hline $\begin{array}{l}\text { Diminuir abuso da polícia - atuação na } \\
\text { escola }\end{array}$ & 2 & 0,2 \\
\hline Prevenir em relação ao consumo de drogas & 27 & 2,4 \\
\hline $\begin{array}{l}\text { Prevenir doenças sexualmente transmissí- } \\
\text { veis (DST)/HIV (dar cursos/palestras/clínica) }\end{array}$ & 34 & 3,0 \\
\hline $\begin{array}{l}\text { Prevenir gravidez na adolescência (dar } \\
\text { cursos/palestras/clínica) }\end{array}$ & 22 & 1,9 \\
\hline Elevar auto-estima & 46 & 4,0 \\
\hline Promover o protagonismo juvenil & 88 & 7,7 \\
\hline $\begin{array}{l}\text { Criar/manter espaços/fóruns de debates } \\
\text { sobre jovens }\end{array}$ & 44 & 3,8 \\
\hline Propiciar inclusão digital & 7 & 0,6 \\
\hline $\begin{array}{l}\text { Reintegrar crianças e jovens em processo } \\
\text { de exclusão }\end{array}$ & 110 & 9,6 \\
\hline $\begin{array}{l}\text { Formular políticas municipais de apoio à } \\
\text { criança e ao jovem }\end{array}$ & 8 & 0,7 \\
\hline Realizar pesquisa & 4 & 0,3 \\
\hline Desmarginalizar a cultura hip-hop & 4 & 0,3 \\
\hline Outros & 142 & 12,4 \\
\hline Não informado & 11 & 1,0 \\
\hline Total & 1148 & 100,0 \\
\hline
\end{tabular}

* Múltipla escolha 
unidades de ensino, o paralelismo das ações provavelmente teria pouco a oferecer no sentido da alteração dessa relação conflituosa.

No tocante aos recursos, verifica-se que a área pública ainda é majoritária na manutenção financeira das ações, já que pouco mais de $80 \%$ dos programas contam com recursos públicos de diferentes esferas. Entretanto, o município aparece como parceiro na maioria dos projetos $(60,3 \%)$, seguido pelo poder federal $(14,2 \%)$ e estadual $(6,4 \%)$ (Tabela 8$).{ }^{16}$

Tabela 8 - Origem dos recursos

\begin{tabular}{|l|r|r|}
\hline \multicolumn{1}{|c|}{ Origem* } & Freqüência & \multicolumn{1}{c|}{$\%$} \\
\hline Recursos federais & 160 & 14,2 \\
Recursos estaduais & 72 & 6,4 \\
Recursos municipais & 680 & 60,3 \\
Sociedade civil organizada & 65 & 5,8 \\
Empresas privadas & 65 & 5,8 \\
Recursos internacionais & 11 & 1,0 \\
Cobrança de ingresso & 2 & 0,2 \\
Cobrança de taxa dos usuários & 2 & 0,2 \\
Não informado & 32 & 2,8 \\
Outras fontes & 39 & 3,3 \\
\hline Total & 1128 & 100,0 \\
\hline
\end{tabular}

* Múltipla Escolha

Cerca de $70 \%$ dos projetos declararam a existência de parcerias, que podem ser de natureza variada, além da financeira. Vale lembrar que a prefeitura, além de sempre figurar como responsável pelos recursos financeiros, também oferece espaços e, muitas vezes, apoio técnico (Tabela 9).

Tabela 9 - Parcerias

\begin{tabular}{|l|c|r|}
\hline \multicolumn{1}{|c|}{ Parceria } & Freqüência & $\%$ \\
\hline Sim & 549 & 69,0 \\
Não & 247 & 31,0 \\
\hline Total & 796 & 100,0 \\
\hline
\end{tabular}

${ }^{16}$ Vale a pena assinalar a importância do poder federal na constituição de um discurso capaz de sustentar as ações, discurso que é, em grande parte, reiterado pelos municípios, mesmo que do ponto de vista material a participação do poder federal não seja majoritária.
Os programas, de acordo com os dados disponíveis, são híbridos quanto às faixas etárias. Uma primeira classificação evidencia que há um grande número que congrega crianças e adolescentes $(30 \%)$, e outros que não estabelecem recortes, reunindo crianças, adolescentes e jovens (26\%). Uma parcela dedicase apenas aos adolescentes (13\%). Poderíamos então considerar que cerca de $40 \%$ trabalham com a faixa etária prescrita pelo ECA. As ações que atendem de modo específico a adolescentes e jovens, sem aglutinação com outras faixas etárias $(25 \%)$, começam a fazer-se presentes, embora apenas $3,9 \%$ dos programas ofereçam atendimento específico para jovens entre 18 e 29 anos. Observa-se, assim, uma predominância de ações voltadas para adolescentes, quando as crianças não estão envolvidas (Tabela 10).

Tabela 10 - Faixa etária do público alvo dos programas

\begin{tabular}{|l|r|r|}
\hline \multicolumn{1}{|c|}{ Faixa etária } & FA & $\%$ \\
\hline 7 a 17 & 241 & 30,3 \\
7 a 29 & 212 & 26,6 \\
14 a 17 & 106 & 13,3 \\
14 a 29 & 198 & 24,9 \\
18 a 29 & 31 & 3,9 \\
Não respondido & 8 & 1,0 \\
\hline Total & 796 & 100,0 \\
\hline
\end{tabular}

Essa é uma situação observada na maioria das regiões metropolitanas investigadas. A freqüência maior de ações destinadas à faixa etária prevista pelo ECA, reunindo crianças e adolescentes em um mesmo projeto, promove, ao menos inicialmente, certa indiferenciação das especificidades do ciclo de vida, ou seja, está pressuposta a idéia de que crianças e adolescentes são o público-alvo porque estariam, em princípio, dentro dos marcos estabelecidos pela legislação. Ocorre que houve, nos contatos com as prefeituras e respectivos gestores de programas, pouca percepção das implicações das significativas diferenças existentes entre demandas, experiências e necessidades de crianças com 9 anos de idade e adolescentes na faixa dos 17. Além disso, alguns técnicos voltados para a implantação dos direitos previstos na 
lei ressentem-se da descontinuidade e da exclusão de muitos jovens da freqüência a programas apenas porque atingiram a maioridade legal.

Mas a disseminação de ações, reunindo adolescentes (14 a 17 anos) e jovens (15 a 29 anos), implica não só um alargamento da temporalidade do ciclo de vida que merece a ação do Poder Público, mas também a verificação de que as possíveis divisões etárias desse contingente não impedem o reconhecimento de maior número de afinidades do que dissonâncias. Ou seja, é possível reunir adolescentes e jovens em um mesmo programa, o que seria, provavelmente, uma ação mais adequada do que trazer os adolescentes para o universo da infância, o que acabaria por descaracterizar não só a infância, tal qual foi concebida pela modernidade, como a própria adolescência e juventude como momentos diversos construídos historicamente na sociedade moderna a partir do século XIX. No entanto, outras implicações existem, porque os marcos legais da maioridade são arbitrários, produto de consensos provisórios, e não deveriam implicar restrição da ação do Estado, pois deixam à sombra categorias significativas de jovens sobre as quais o Poder Público no Brasil não assume qualquer responsabilidade.

Se relacionarmos a área de atividade por faixa etária, um quadro mais preciso pode ser delineado (Tabela 11). Na faixa dos 7 aos 17 anos, as áreas mais significativas são as de reinserção social $(30,8 \%)$ e esporte e lazer $(23,3 \%)$. Isso nos permite relacionar esses projetos com preocupações relativas ao cuidado e à ocupação do tempo livre com atividades de integração e lazer, limitando-se à faixa etária prevista pelo ECA.

Já nos projetos que consideraram a faixa dos 14 aos 29 anos, cuja atuação aparece orientada mais claramente para a juventude, a modalidade de ação mais freqüente é o protagonismo juvenil, com $24,7 \%$ das citações. Essas ações podem indicar um possível alargamento do discurso em torno da participação do jovem, embora não possam ser identificados os pressupostos dessa orientação. Não cabe neste momento distinguir conceitualmente, mas assinalar que há substantivas diferenças entre o termo protagonismo e a expressão participação, sinalizando práticas e orientações diversas. A expressão protagonismo juvenil difundiuse nos anos de 1990 e já vem sendo objeto de várias críticas (Castro, 2002; Ferreti, Zibas \& Tartuce, 2004). Em geral, o protagonismo tem aparecido como um princípio educativo a partir do qual os jovens deixam de ser vistos como meros aprendizes e passam a ser concebidos como sujeitos que podem agir no ambiente em que vivem, alcançando autonomia na suas ações (Corti \& Souza, 2005). Essa noção, ao operar como um princípio educativo no interior de uma ação, pode levar ao deslocamento do sentido sociopolítico, voltado para os mecanismos de participação que incidem

Tabela 11 - Área de atividade por faixa etária

\begin{tabular}{|c|c|c|c|c|c|c|c|c|c|c|c|c|}
\hline \multirow{2}{*}{ Área de atividade } & \multicolumn{2}{|c|}{7 a 17} & \multicolumn{2}{|c|}{7 a 29} & \multicolumn{2}{|c|}{14 a 17} & \multicolumn{2}{|c|}{14 a 29} & \multicolumn{2}{|c|}{18 a 29} & \multicolumn{2}{|c|}{ NR } \\
\hline & FA & $\%$ & FA & $\%$ & FA & $\%$ & FA & $\%$ & FA & $\%$ & FA & $\%$ \\
\hline Esporte e lazer & 56 & 23,3 & 31 & 14,6 & 8 & 7,5 & 14 & 7,1 & 3 & 9,7 & 2 & 22,2 \\
\hline Cultura & 39 & 16,3 & 56 & 26,4 & 7 & 6,6 & 47 & 23,7 & 4 & 12,9 & $\mathbf{0}$ & 0,0 \\
\hline Saúde & 17 & 7,1 & 33 & 15,6 & 7 & 6,6 & 20 & 10,1 & 2 & 6,5 & 1 & 11,1 \\
\hline Mundo do trabalho & 7 & 2,9 & 7 & 3,3 & 21 & 19,8 & 29 & 14,6 & 4 & 12,9 & $\mathbf{0}$ & 0,0 \\
\hline Reinserção social & 74 & 30,8 & 29 & 13,7 & 37 & 34,9 & 20 & 10,1 & 6 & 19,4 & $\mathbf{0}$ & 0,0 \\
\hline Protagonismo juvenil & 11 & 4,6 & 19 & $\mathbf{9 , 0}$ & 18 & 17,0 & 49 & 24,7 & 6 & 19,4 & $\mathbf{0}$ & 0,0 \\
\hline Escolarização & 12 & 5,0 & $\mathbf{5}$ & 2,4 & $\mathbf{0}$ & 0,0 & 2 & 1,0 & 1 & 3,2 & 4 & 44,5 \\
\hline Educação ambiental & 1 & 0,4 & 7 & 3,3 & 1 & 0,9 & $\mathbf{0}$ & 0,0 & $\mathbf{0}$ & 0,0 & $\mathbf{0}$ & 0,0 \\
\hline Pesquisa & 1 & 0,4 & 4 & 1,9 & $\mathbf{0}$ & 0,0 & 1 & 0,5 & $\mathbf{0}$ & 0,0 & $\mathbf{0}$ & 0,0 \\
\hline Produção literária & 1 & 0,4 & 4 & 1,9 & $\mathbf{0}$ & 0,0 & 2 & 1,0 & $\mathbf{0}$ & 0,0 & $\mathbf{0}$ & 0,0 \\
\hline Atividades religiosas & $\mathbf{0}$ & 0,0 & $\mathbf{0}$ & 0,0 & $\mathbf{0}$ & 0,0 & $\mathbf{0}$ & 0,0 & $\mathbf{0}$ & 0,0 & $\mathbf{0}$ & 0,0 \\
\hline Outros & 14 & 5,9 & 14 & 6,6 & 5 & 4,7 & 10 & 6,2 & 4 & 12,9 & $\mathbf{0}$ & 0,0 \\
\hline Não respondido & 7 & 2,9 & 3 & 1,3 & 2 & 2,0 & 2 & 1,0 & 1 & 3,1 & 2 & 22,2 \\
\hline Total & 240 & 100,0 & 212 & 100,0 & 106 & 100,0 & 198 & 100,0 & 31 & 100,0 & 9 & 100,0 \\
\hline
\end{tabular}


sobre a capacidade dos atores de partilhar, coletivamente, das decisões que dizem respeito aos seus interesses no âmbito da esfera pública.

Outra área a registrar ações para essa faixa etária é o mundo do trabalho (14,6\%), abrangendo desde propostas que visem ao adiamento da entrada do jovem no mercado de trabalho até a sua profissionalização. Podemos aferir que o desemprego começa a tomar conta da pauta política do poder municipal, embora as iniciativas e os pressupostos sejam variados, conforme observamos anteriormente. Na faixa dos 7 aos 29 anos, a mais indiferenciada, a oferta maior incide sobre as áreas de cultura $(26,4 \%)$, saúde $(15,6 \%)$ e esporte e lazer $(14,6 \%)$.

De acordo com declarações dos entrevistados, grande parte das atividades prevê formas de avaliação, conforme verifica-se nos dados contidos nas Tabelas 12 e 13. Uma vez que a maioria está em fase de execução, a previsão de práticas de avaliação no fim da ação aparece muito mais como um elemento de vontade política do que como uma orientação já consolidada.

Tabela 12 - Prática de avaliação

\begin{tabular}{|l|r|r|}
\hline & FA & $\%$ \\
\hline Sim & 715 & 89,0 \\
Não & 81 & 11,0 \\
\hline Total & 796 & 100,0 \\
\hline
\end{tabular}

Tabela 13 - Mecanismos de avaliação dos usuários ao final do programa

\begin{tabular}{|l|c|r|}
\hline $\begin{array}{l}\text { Mecanismos } \\
\text { de avaliação }\end{array}$ & Freqüência & $\%$ \\
\hline Sim & 478 & 60,1 \\
Não & 313 & 39,3 \\
Não informado & 5 & 0,6 \\
\hline Total & 796 & 100,0 \\
\hline
\end{tabular}

O tema da participação pode ser mais um indicador do caráter das práticas, ainda distantes de um universo mais democrático na constituição das ações do poder municipal. Na concepção do programa, a maioria declara que o público-alvo não participa, ou seja, de um total de 796 projetos, $60 \%$ declararam que não houve participação (Tabela 14). A participação, de modo predominante, é entendida como "dar sugestões".

Tabela 14 - Participação do público alvo na elaboração do programa

\begin{tabular}{|l|c|r|}
\hline \multicolumn{1}{|c|}{ Parceria } & Freqüência & $\%$ \\
\hline Sim & 321 & 40,3 \\
Não & 475 & 59,7 \\
\hline Total & 796 & 100,0 \\
\hline
\end{tabular}

Tabela 15 - Participação da sociedade civil na concepção/elaboração das ações

\begin{tabular}{|l|r|r|}
\hline \multicolumn{1}{|c|}{ Participam } & FA & $\%$ \\
\hline Sim & 273 & 34,3 \\
Não & 502 & 63,1 \\
Não respondido & 21 & 2,6 \\
\hline Total & 796 & 100,0 \\
\hline
\end{tabular}

Tabela 16 - Tipos de atores da sociedade civil*

\begin{tabular}{|l|r|r|}
\hline Atores & $\mathrm{N}$. & \multicolumn{1}{|c|}{$\%$} \\
\hline Associações de moradores & 65 & 22,8 \\
Movimento estudantil & 43 & 15,1 \\
Associações empresariais & 27 & 9,4 \\
Grupos juvenis & 32 & 11,2 \\
Movimentos sindicais & 1 & 0,3 \\
Igrejas & 26 & 9,1 \\
Partidos & 6 & 2,1 \\
Organizações não-governamentais & 8 & 2,8 \\
Conselhos locais & 5 & 1,8 \\
Escolas/universidades & 6 & 2,1 \\
Associações/sociedade civil organizada & 5 & 1,8 \\
Grupos culturais/artísticos & 5 & 1,8 \\
Grupos esportistas & 5 & 1,8 \\
Coletivo de mulheres & 2 & 0,7 \\
Voluntários & 1 & 0,3 \\
Não respondido & 22 & 7,8 \\
Outros & 26 & 9,1 \\
\hline Total & 285 & 100,0 \\
\hline * Múltipla escolha & \multicolumn{2}{|l}{}
\end{tabular}

Se os usuários não estão presentes na elaboração, essa situação poderia ser atenuada com o tema mais amplo da participação da sociedade civil. Se for considerada a concepção dos programas (Tabela 15), existe pouquíssima presença de atores externos ao Executivo municipal: somente $34 \%$ responderam afirmativamente. No entanto, quando há esse grau de 
abertura, verifica-se uma presença significativa de coletivos juvenis como atores importantes para essa interação, sendo mais freqüentes os jovens organizados em torno do movimento estudantil, ao lado de Igrejas e associações de moradores (Tabela 16).

Os índices melhoram na execução dos projetos, uma vez que $66 \%$ afirmam ter algum tipo de participação, conforme pode ser observado nos dados da Tabela 17. No entanto, a participação dos grupos juvenis nesse momento é menos freqüente, sendo mais significativas as associações de moradores, Igrejas e entidades empresariais (Tabela 18).

Tabela 17 - Participação da sociedade civil na implementação

\begin{tabular}{|l|r|r|}
\hline \multicolumn{1}{|c|}{ Participam } & FA & $\%$ \\
\hline Sim & 396 & 66,0 \\
Não & 377 & 31,8 \\
Não respondido & 23 & 2,2 \\
\hline Total & 796 & 100,0 \\
\hline
\end{tabular}

Tabela 18 - Tipo de atores*

\begin{tabular}{|l|r|r|}
\hline \multicolumn{1}{|c|}{ Atores } & $\mathrm{N}$ & \multicolumn{1}{c|}{$\%$} \\
\hline Associações de moradores & 144 & 18,5 \\
Movimento estudantil & 85 & 11,0 \\
Associações empresariais & 93 & 12,0 \\
Grupos juvenis & 101 & 13,0 \\
Movimentos sindicais & 26 & 3,3 \\
Igrejas & 136 & 17,5 \\
Partidos & 31 & 4,0 \\
Organizações não-governamentais & 24 & 3,1 \\
Conselhos locais & 7 & 1,0 \\
Escolas/universidades & 19 & 2,4 \\
Associações/sociedade civil organizada & 8 & 1,0 \\
Grupos culturais/artísticos & 9 & 1,1 \\
Grupos esportistas & 7 & 1,0 \\
Coletivo de mulheres & 3 & 0,4 \\
Voluntários & 2 & 0,2 \\
Não respondido & 25 & 3,2 \\
Outros & 57 & 7,3 \\
\hline Total & 777 & 100,0 \\
\hline
\end{tabular}

* Múltipla escolha

\section{A transferência de renda para jovens}

Um aspecto inovador das ações destinadas aos jovens reside em um conjunto de projetos ou programas que envolvem algum tipo de renda. Em vez de considerá-las assistenciais, compensatórias, inclusivas, preferimos, ao menos provisoriamente, denominá-las de mecanismos de transferência de renda.

Dos 796 programas de juventude levantados pela pesquisa, cerca de $37,1 \%$ contam com a presença de estagiários ou bolsistas (Tabela 19). Entre aqueles que declararam afirmativamente, 91,5\% pressupõem alguma forma de remuneração (Tabela 20).

Tabela 19 - Existência de estagiários

\begin{tabular}{|l|c|r|}
\hline $\begin{array}{l}\text { Conta com } \\
\text { estagiários }\end{array}$ & Freqüência & $\%$ \\
\hline Sim & 295 & 37,1 \\
Não & 442 & 55,5 \\
Não respondido & 59 & 7,4 \\
\hline Total & 796 & 100,0 \\
\hline
\end{tabular}

Tabela 20 - Existência de remuneração

\begin{tabular}{|l|c|r|}
\hline Remuneração & Freqüência & $\%$ \\
\hline Sim & 270 & 91,5 \\
Não & 24 & 8,1 \\
Não informado & 1 & 0,4 \\
\hline Total & 295 & 100,0 \\
\hline
\end{tabular}

Os benefícios oferecidos pelos 270 projetos diferem quanto à sua forma: $67,8 \%$ transferem renda na forma de salário mensal, $18,9 \%$ por meio de bolsas e 7,0\% mediante prestação de serviços (Tabela 21). Os recursos financeiros para o pagamento dos estagiários ou para execução dos programas são, em sua maioria, oriundos, respectivamente, dos governos municipais $(61,3 \%)$ e do governo federal $(28,2 \%)$ (Tabela 22).

Tabela 21 - Tipo de remuneração

\begin{tabular}{|l|c|r|}
\hline Remuneração & Freqüência & $\%$ \\
\hline Salário mensal & 183 & 67,8 \\
Bolsa & 51 & 18,9 \\
Prestação de serviços & 19 & 7,0 \\
Outros & 1 & 0,4 \\
Não informado & 16 & 5,9 \\
\hline Total & 270 & 100,0 \\
\hline
\end{tabular}

Como se pode observar na Tabela 23, as Regiões Metropolitanas de Florianópolis, São Paulo e Porto 
Alegre apresentam maior número de programas nessa modalidade.

Tabela 22 - Origem dos recursos*

\begin{tabular}{|l|r|r|}
\hline \multicolumn{1}{|c|}{ Origem } & Freqüência & \multicolumn{1}{c|}{$\%$} \\
\hline Federal & 81 & 28,2 \\
Estadual & 26 & 9,1 \\
Municipal & 176 & 61,3 \\
Sociedade civil & 1 & 0,4 \\
Outras fontes & 3 & 1,0 \\
\hline Total & 287 & 100,0 \\
\hline
\end{tabular}

* Múltipla escolha

Tabela 23 - Concentração de programas com transferência de renda por região metropolitana

\begin{tabular}{|l|c|c|}
\hline $\begin{array}{c}\text { Região } \\
\text { Metropolitana }\end{array}$ & Freqüência & $\%$ \\
\hline SP & 57 & 21,1 \\
ES & 45 & 16,7 \\
RS & 45 & 16,7 \\
GO & 38 & 14,1 \\
RJ & 28 & 10,4 \\
PE & 27 & 10,0 \\
SC & 15 & 5,6 \\
SP/ABC & 9 & 3,3 \\
MG & 6 & 2,1 \\
\hline Total & 270 & 100,0 \\
\hline
\end{tabular}

Se for considerado o momento da execução, verifica-se que a gestão 2001-2004 aparece como o período mais expressivo desse tipo de iniciativa, que teve início nos anos de 1990 (Tabela 24).

Tabela 24 - Data de início dos programas

\begin{tabular}{|l|r|r|}
\hline $\begin{array}{c}\text { Data de início } \\
\text { dos programas }\end{array}$ & Freqüência & $\%$ \\
\hline Entre 1987 e 1996 & 58 & 21,5 \\
1997 & 12 & 4,4 \\
1998 & 21 & 7,8 \\
1999 & 11 & 4,1 \\
2000 & 20 & 7,4 \\
2001 & 57 & 21,1 \\
2002 & 40 & 14,8 \\
2003 & 48 & 17,8 \\
$2004 *$ & 3 & 1,1 \\
\hline Total & 270 & 100,0 \\
\hline
\end{tabular}

* O trabalho de campo encerrou-se em fevereiro de 2004.
As ações que contemplam algum tipo de remuneração têm algumas características bem marcantes: mais da metade dos projetos levantados pela pesquisa, cerca de $60 \%$, funciona diariamente e o restante oscila entre encontros semanais, mensais ou sem periodicidade. Ao investigar o principal tipo de atividade desenvolvida por programas de transferência de renda, foi possível observar que a grande concentração dessas atividades se encontra nas seguintes modalidades: oficinas $(23,3 \%)$, cursos $(16,7 \%)$ e palestras $(14,4 \%)$. Esse conjunto compõe um tipo de estratégia bastante formal, apresentando fortes feições educativas (Tabelas 25 e 26).

Tabela 25 - Funcionamento dos programas

\begin{tabular}{|l|r|r|}
\hline Funcionamento & Freqüência & $\%$ \\
\hline Diário & 162 & 60,0 \\
Semanal & 46 & 17,0 \\
Mensal & 9 & 3,3 \\
Por encontros & 29 & 10,7 \\
Outros & 19 & 7,0 \\
Não informado & 5 & 2,0 \\
\hline Total & 270 & 100,0 \\
\hline
\end{tabular}

Tabela 26 - Atividades desenvolvidas pelo programa

\begin{tabular}{|l|c|r|}
\hline \multicolumn{1}{|c|}{ Atividade } & Freqüência & $\%$ \\
\hline Palestras & 39 & 14,4 \\
Cursos & 45 & 16,7 \\
Oficinas & 63 & 23,3 \\
Atividade & & \\
psicoterapêutica & 20 & 7,4 \\
Shows & 16 & 5,9 \\
Exposições & 5 & 1,9 \\
Mostras & 4 & 1,5 \\
Concursos & 2 & 0,7 \\
Campeonatos & 20 & 7,4 \\
Viagens & 3 & 1,1 \\
Outras & 40 & 14,8 \\
Não informado & 13 & 4,9 \\
\hline Total & 270 & 100,0 \\
\hline
\end{tabular}

A natureza das atividades previstas contempla um número expressivo de ações voltadas para a reinserção social (25,9\% das ações), seguidas pelas práticas artísticas $(18,2 \%)$ e esportivas $(10 \%)$, como pode ser observado na Tabela 27. 
Tabela 27 - Modalidades de atividades

\begin{tabular}{|l|r|r|}
\hline \multicolumn{1}{|c|}{ Atividade } & Freqüência & \multicolumn{1}{c|}{$\%$} \\
\hline Esportes & 27 & 10,0 \\
Teatro & 13 & 4,8 \\
Música & 14 & 5,2 \\
Dança & 5 & 1,9 \\
Artes plásticas & 17 & 6,3 \\
Saúde & 22 & 8,1 \\
Qualificação profissional & 25 & 9,3 \\
Lazer & 9 & 3,3 \\
Acompanhamento e reinserção & 70 & 26,0 \\
Estímulo à participação & 26 & 9,6 \\
Assistência e acompanhamento & & \\
psicoterapêutico & 4 & 1,5 \\
Outros & 29 & 10,7 \\
Não informado & 9 & 3,3 \\
\hline Total & 270 & 100,0 \\
\hline
\end{tabular}

Poderíamos considerar dois tipos de situação: o primeiro diz respeito a um conjunto importante de programas que contratam estagiários ou bolsistas, em sua grande maioria jovens, para trabalhar como animadores culturais, monitores ou educadores sociais. Essa modalidade tanto pode encontrar na prefeitura o próprio agente recrutador, como pode ser empreendida por associações ou organizações não-governamentais parceiras na execução de projetos. Trata-se de um tipo de ocupação voltada para jovens das classes médias, mas também de origem popular, muitas vezes universitários que ainda não completaram sua formação profissional. ${ }^{17}$ Esse é um aspecto pouco estudado, pois cria alternativas de ocupação para setores mais escolarizados em ações cujo foco seria aqueles mais penalizados pelos processos de exclusão. Cidades como Recife, com os animadores culturais, e São Paulo, com os monitores do Programa Trabalho, constituem exemplos importantes que demandam novas investigações (gestão 2001-2004).

Mas algumas questões podem ser examinadas de um outro ponto de vista, ou seja, os programas que assegurem algum tipo de auxílio pecuniário aos jovens ou adolescentes usuários são insuficientemente

${ }^{17}$ Muitos foram usuários de programas anteriores, tendo uma trajetória pessoal de envolvimento com esse tipo de ação. avaliados, seus impactos ainda são desconhecidos em meio à diversidade de orientações tanto na sua concepção como no momento de sua implantação.

As iniciativas mais visíveis tiveram início no segundo mandato do Governo Fernando Henrique Cardoso, e disseminaram-se em várias cidades. Outras nasceram no Executivo municipal, como é o caso do Programa Bolsa Trabalho da Prefeitura Municipal de São Paulo. No entanto, a ação mais disseminada é o Programa Agente Jovem de Desenvolvimento Social e Humano. Criado em 2000, no âmbito da Secretaria de Estado de Assistência Social (SEAS), vinculou-se ao Plano Nacional de Segurança Pública, mais especificamente a um dos seus compromissos, relacionado à intensificação das ações de prevenção ao fenômeno da violência no interior do Programa Nacional de Direitos Humanos. O Agente Jovem foi mantido no Governo Lula e atinge cerca de 50.000 jovens no Brasil (Brasil, Ministério da Previdência e Assistência Social - MPAS, 2001a, 2001b).

Em sua implementação são envolvidas as três esferas de governo - federal, estadual e municipal -, com atribuições diferentes. Enquanto aos dois primeiros cabem a concepção, o monitoramento, a assessoria, a avaliação e a definição dos municípios a serem atendidos, os municípios responsabilizam-se pela execução direta ou por meio de parcerias com universidades ou organizações não-governamentais. A garantia dos recursos é de responsabilidade do governo federal, mas conta com a participação das duas outras esferas e parcerias com a iniciativa privada.

Seu "público-alvo" é constituído por "adolescentes carentes" de 15 a 17 anos, em situação de risco social, vivendo em famílias com renda per capita de até meio salário mínimo, moradores de todas as capitais e vários municípios do país que apresentassem menores índices de desenvolvimento humano. A prioridade desenhava um tipo de adolescente, aquele que estivesse fora da escola e/ou em liberdade assistida ou egresso de programas sociais.

No momento da sua formulação, o Programa estabelecia como desafio a construção de uma proposta dirigida a determinado segmento juvenil que, não ten- 
do idade adequada para ingressar no mercado de trabalho e para o qual era reconhecida uma escassez de programas, estaria, conseqüentemente, mais exposto à marginalidade. Para seus idealizadores, os jovens moradores de localidades empobrecidas não dispunham de grandes alternativas e também não contavam com programas de atendimento tendo em vista sua faixa etária. Não apresentavam, também, idade suficiente para entrar no mercado de trabalho e, assim, permaneceriam sujeitos à ociosidade e à marginalidade (Brasil, MPAS, 2001a).

Depreende-se dessa formulação a necessidade de construir um programa que pudesse "ocupar" esses jovens, retirando-os da situação de "risco" em que se encontravam. Resumidamente, o Programa estabelece como objetivos específicos: apoiar os jovens no planejamento e na construção de seu futuro; resgatar seus vínculos familiares, comunitários e sociais; oferecer-lhes instrumentos para que pudessem desenvolver ações comunitárias; prepará-los para o ingresso no mundo do trabalho; contribuir para a melhoria dos indicadores sociais na comunidade, por meio de sua atuação; garantir sua inserção ou reinserção no sistema educacional (Brasil, MPAS, 2001b).

Ao longo de um período de doze meses os jovens, além de se manterem na escola, devem freqüentar cursos de capacitação (seis meses) e implantar projetos de intervenção em suas comunidades (seis meses), prioritariamente nas áreas de saúde, cultura, meio ambiente, cidadania, esporte e turismo. Durante todo o período, recebem uma bolsa mensal no valor de $\mathrm{R} \$ 65,00^{18}$ e são acompanhados por "facilitadores" - profissionais de diferentes áreas que ministram aulas e "orientadores sociais" -, preferencialmente estudantes universitários que deveriam possuir experiência de trabalho com jovens, responsabilizando-se por facilitar a ação social juvenil.

Seguindo essa breve descrição, é claramente perceptível a imagem do jovem como fonte e vítima de problemas sociais e, ao mesmo tempo, como prota-

${ }^{18}$ Esse valor continua inalterado. gonista do desenvolvimento de sua "comunidade". Quanto à primeira imagem, trata-se de pensar projetos para jovens considerados pouco integrados socialmente, sobretudo nas instituições mais tradicionais, e por isso fortemente sujeitos ao risco social.

Mas também é preciso não esquecer da tarefa que o Projeto impõe ao adolescente. Uma vez adequadamente preparado e formado, aquele jovem carente, pouco escolarizado, sem trabalho, fragilmente vinculado à sua família e à sociedade, sujeito à marginalidade e vivendo em situação de risco social, pode e deve ser estimulado a contribuir para a melhoria das condições de vida de sua comunidade a partir de uma determinada intervenção social para a qual será orientado, sendo considerado elemento ativo de seu desenvolvimento (Brasil, MPAS, 2001a).

No ano de 2001, a reformulação de alguns aspectos do Programa deixa ainda mais clara a importância do protagonismo juvenil e o papel do mundo adulto. O protagonismo é entendido como uma forma de estimular que o jovem possa construir sua autonomia, por intermédio da criação de espaços e de situações propiciadoras da sua participação criativa construtiva e solidária (idem).

Embora nesses trechos reconheça-se certo potencial juvenil, o que poderia ser considerado um avanço no campo das políticas públicas, são visíveis seus limites: primeiramente, a ênfase em certos aspectos comportamentais - como se todo e qualquer jovem em qualquer momento histórico e social fosse naturalmente predisposto a provocar mudanças; em segundo lugar, não explicitar que o jovem será agente de mudança se o mundo adulto reconhecer e criar condições para isso; por fim, atribuir ao jovem uma dificílima tarefa - a de transformar a sua "comunidade", deixando de reconhecê-lo ao mesmo tempo como sujeito de direitos. Ou seja, as ações em sua direção parecem ser mais importantes pelo que podem trazer de benefícios à sociedade do que em relação à garantia de seus direitos enquanto cidadãos.

Assim, como contrapartida ao recebimento da bolsa, é preciso, além da continuidade da trajetória escolar, o envolvimento em ações e capacitações vol- 
tadas para a "comunidade". De certo modo, esperase que as capacitações também permitam ao jovem algum tipo de inserção futura no mercado de trabalho. Ora, nem o número de horas destinadas a elas, nem o perfil dos profissionais que atuam junto aos jovens, parecem garantir essa possibilidade.

Avaliação realizada pelo Tribunal de Contas da União (TCU) em 300 municípios, em 2004, aponta como um dos aspectos bastante frágil do Agente Jovem o perfil dos facilitadores e orientadores sociais: em apenas $19 \%$ dos casos a equipe técnica tinha perfil adequado (Brasil, TCU, 2004).

Além disso, ainda segundo essa avaliação, em muitos municípios os "agentes jovens" estavam desempenhando tarefas que pouco ou nada condiziam com os objetivos do Programa, como serviços de limpeza, datilografia, entre outros. A despeito dos benefícios percebidos em termos de desenvolvimento pessoal, social e comunitário dos usuários, a falta de continuidade é apontada como uma das dificuldades para que a ação cumpra seus objetivos de inclusão social.

Em estudo realizado em Vitória, Camacho (2004) verificou uma forte tensão entre equipes técnicas e adolescentes relacionada à situação e condição juvenis. Ora as equipes técnicas viam os jovens quase como crianças, incapazes de assumir responsabilidades, como declara uma das adolescentes usuárias, instalando entre eles uma certa "moratória social", ora como adultos, quando lhes eram demandadas "condutas adequadas como agente jovem" pela equipe técnica.

Embora com todas essas limitações, o Programa Agente Jovem atendeu 57.000 jovens no país, e o novo governo parece ter mantido seus objetivos básicos, como podemos observar no trecho a seguir: "Mais de 55 mil jovens que viviam em situação de pobreza e risco, passando os dias fora da escola ou fazendo pequenos trabalhos nas ruas, agora estão ajudando a melhorar a vida da comunidade onde moram. São os adolescentes beneficiados pelo Programa Agente Jovem do Ministério do Desenvolvimento Social e Combate à Fome" (Brasil, MDS, 2004).
No levantamento realizado, o Agente Jovem esteve presente em todas as regiões metropolitanas investigadas.

\section{Tabela 27 - Programa Agente Jovem por região metropolitana}

\begin{tabular}{|l|c|}
\hline \multicolumn{1}{|c|}{ Região Metropolitana } & FA \\
\hline Recife & 5 \\
Goiânia & 1 \\
Porto Alegre & 6 \\
Florianópolis & 1 \\
Vitória & 6 \\
Belo Horizonte & 9 \\
São Paulo & 5 \\
ABC & 1 \\
Rio de Janeiro & 6 \\
\hline Total & 40 \\
\hline
\end{tabular}

O tipo de ação desenvolvida pelo Programa Agente Jovem assenta-se sobre um tripé que tende a generalizar-se em diversos programas públicos, ou mesmo aqueles empreendidos por organismos da sociedade civil: em todos há uma previsão de transferência de recursos que aparece como uma distribuição de renda, com a necessária contrapartida ${ }^{19}$ dividida em dois aspectos: a freqüência obrigatória à escola e a exigência de participação em atividades de cunho socioeducativo, em geral oferecidas por organizações não-governamentais parceiras.

Todos os gestores reconhecem, e as avaliações iniciais identificam, que as atividades em geral são realizadas a partir de uma base material precária e com um corpo de responsáveis de baixa formação técnica

${ }^{19}$ A idéia de contrapartida restitui uma das questões fundamentais pouco analisadas nos programas que envolvem distribuição de renda. Trata-se de promoção de justiça e, portanto, um direito incondicional de renda mínima (presente na acepção de Eduardo Suplicy), ou trata-se de uma transferência, sob condições, configurada na idéia de uma restituição obrigatória em serviços e práticas por parte do cidadão ou dos grupos beneficiados? (Sposito \& Corrochano, 2005). No âmbito europeu, essa discussão tem sido feita há algumas décadas; a esse respeito, consultar Benarroch (1998). 
ou mesmo escolar. Trata-se daquilo que Leão (2004) denomina de "pedagogia da precariedade", reunindo um conjunto de propostas no campo da "educação nãoconvencional" (Camacho, 2004), que sempre envolve palestras, cursos e oficinas. Às vezes os programas pressupõem uma formação geral, voltada para a cidadania, e outra voltada para o aprendizado de habilidades articuladas ao mundo do trabalho. Mas nesse conjunto inscreve-se, também, a obrigatoriedade da prestação de serviços à comunidade, ou o desenvolvimento de atividades comunitárias tidas como úteis e importantes para os bairros onde esses jovens residem.

Algumas tensões precisam ser apontadas, de modo que configurem um campo amplo de questões com base na nova realidade gestada por essas ações:

\section{- Grupo alvo e escolaridade}

Os programas pressupõem a simples obrigatoriedade da matrícula na escola pública como fator de inclusão, o que não deixa de ser, ao menos, curioso. Os usuários são definidos com base nas condições de maior vulnerabilidade e pobreza. Nesses grupos situam-se, também, os jovens precocemente excluídos da escola com significativa distorção série/idade. A mera exigência de retorno à mesma escola que não é capaz de lidar com essas situações apenas sinaliza a permanência dos processos de exclusão. Dessa constatação duas conseqüências podem ser derivadas: uma é o paralelismo das atividades não-convencionais de caráter socioeducativo que não se articulam com a rede pública de ensino; outra é a total ausência das políticas educacionais articuladas a esses programas, pois elas deveriam ser capazes de redefinir o tipo e a proposta de escolaridade adequada a esses jovens.

- Por que educação não-escolar?20

A imensa maioria dos programas e projetos des-

${ }^{20}$ Camacho (2004) utiliza o termo educação não-convencional, pois considera que recobre melhor o sentido dessas práticas socioeducativas, pois são bastante formalizadas e institucionalizadas, não sendo adequada a idéia de educação não-formal. tinados aos jovens admite e valoriza uma ação de natureza socioeducativa, mas não declara os pressupostos que induzem a essa adesão. Ao que tudo indica, as deficiências que são inscritas nos sistemas de ensino estariam radicadas não só nos aspectos pedagógicos, mas também na missão socializadora da escola, que não estaria formando para a cidadania.

A disseminação dessas propostas estaria praticamente criando uma via paralela de educação não-escolar para adolescentes e jovens pobres, que mereceria ser objeto de debate. Essa via, de fato, estaria proporcionando algo melhor que a escola pública não oferece? Se sim, resta a questão: por que não se articula com o sistema de ensino para, de certo modo, transformá-lo? Se a resposta for negativa, resta a impressão de que uma disseminação de ações educativas em regime de precariedade atenderia, ao que tudo indica, apenas ao propósito de ocupar o tempo livre de jovens e adolescentes nos bairros pobres das grandes cidades. Em geral são atividades realizadas em espaços restritos, pouco aparelhados, reproduzindo práticas muito semelhantes ao universo das escolas de periferia e, em algumas situações, mais empobrecidas.

- Concepções distintas de cidadania

A ênfase na dimensão da cidadania acaba por fazer emergir um conceito de cidadania muito mais ligado a uma idéia de atividade socializadora, marcada pelo civismo e pelo aprendizado de certos valores caros a ele, ou, em uma versão mais amena, importantes para a civilidade. Ao que tudo indica, acabam por ser esvaziados - ou ao menos atenuados - os conteúdos da cidadania ligados à idéia de direitos, prevalecendo a pressuposição de que jovens e adolescentes - pobres - precisam ser atingidos por alguma ação que lhes ensine algo. Permanece submerso o conteúdo da cidadania como direito que privilegiaria a ação pública para a promoção da igualdade. Nesse caso, adolescentes e jovens seriam alvos da ação pública para a promoção da igualdade, porque, em sua maioria, esses jovens foram destituídos de direitos básicos nos domínios da educação, da cultura, do lazer e do esporte, entre outros. 
- A obrigatoriedade da ação voluntária: os jovens com o dever de promover o desenvolvimento de sua comunidade

Os programas, por serem focalizados, atingem principalmente jovens desprovidos de direitos, que vivem em territórios destituídos de serviços básicos, predominando uma quase absoluta ausência do Poder Público. Espera-se que essa população volte à escola pública para concluir seus estudos (sabemos que não são poucas as dificuldades inscritas nessa meta), para participar, quase de modo diário, de atividades educativas, e para promover o desenvolvimento do seu bairro, quando o Estado e outras instituições não o fizeram. Por que esse conjunto de exigências e tais expectativas apenas com jovens pobres? Por que alunos de escolas técnicas federais ou de universidades públicas, usufruindo serviços gratuitos mantidos pelos impostos, não estão também submetidos a qualquer contrapartida comunitária, sabendo-se que teriam melhor capital cultural e social para essa ação? Como é possível promover as identidades locais e solidariedades em programas que, ao focalizar o usuário com base em critérios rígidos de renda, desconhecem as redes nas quais os jovens estão mergulhados?

Ao se esboçar uma compreensão das grandes linhas que ancoram as iniciativas sobre juventude nos municípios investigados, tornam-se mais evidentes os mecanismos que ressaltam imagens diversas sobre categorias sociais difusamente consideradas como juventude. Essas imagens expressam duas grandes orientações: uma primeira, estigmatizada, em torno da noção adolescente pobre, e outra em torno do jovem. Se antes da promulgação do ECA a clivagem existente dava-se entre as crianças e os menores, após quinze anos de organização da sociedade civil é evidente o avanço nas concepções em torno dos direitos da infância. De certo modo, há um forte reconhecimento social do direito de qualquer criança, independentemente de sua condição social, a ter uma família, à escola, a condições de saúde, enfim, o direito à proteção e ao cuidado por parte do Estado. O mesmo não ocorre com a figura do adolescente pobre, sobretudo o homem negro e morador das periferias urbanas de grandes metrópoles brasileiras. Desloca-se para esse sujeito a constituição de uma imagem que impede o reconhecimento social de seus direitos decorrentes de seu momento no ciclo de vida. O modo como são considerados pela opinião pública os adolescentes em conflito com a lei, recolhidos nos sistemas de internação, espraia-se para todos aqueles que estão submersos nos bairros pobres e nas favelas. Nega-se a sua condição de indivíduos em formação e desenvolvimento, com múltiplas possibilidades abertas ao crescimento pessoal ao lado de necessidades amplas no domínio do lazer, da cultura, do esporte, da participação, entre outros. Para esse setor, tratado como vulnerável ou produtor de risco, são reservadas as ações de inserção social, compensatórias e de forte teor socioeducativo. Aos outros, aqueles que podem minimamente usufruir alguns direitos, o termo jovem passa a ser fortemente aplicado. De modo perverso, a idéia de adolescência carrega não só estigmas de natureza psicológica ou patológica, tradicionais em algumas teorias facilmente absorvidas pelo senso comum, como incorpora o estereótipo que designa aqueles que ameaçam a sociedade. A maioria dos programas investigados nesses 74 municípios estabelece essa clivagem, muitas vezes cristalizadas em organismos, atores e discursos diferentes que raramente se comunicam entre si: as ações que cuidam dos adolescentes em situação de vulnerabilidade e de risco social $^{21} \mathrm{e}$ as iniciativas destinadas aos jovens.

${ }^{21}$ Apesar das lutas sociais em torno dos direitos dos adolescentes, empreendidas por educadores, assistentes sociais e psicólogos, ainda prevalece no âmbito público e social uma imagem negativa, expressa nas tentativas cotidianas de alterar os limites da maioridade penal, entre outras ações. Há grupos sérios, comprometidos com a idéia de direitos dos adolescentes, em várias das secretarias municipais, mas o tom predominante nos municípios ainda é a reiteração de percepções cristalizadas em tempos anteriores ao ECA, mesmo que a retórica dominante tenha absorvido novas linguagens. 
É importante considerar que parcelas dos que empreendem programas para adolescentes lutam por imprimir uma imagem mais positiva, calcada na idéia de direitos. Mas os atores responsáveis pelas ações, além do tipo de inscrição que recebem na esfera governamental - em geral na área da assistência ou da inclusão social - não conseguem, apesar dos esforços, romper com um perverso consenso. Desse modo os adolescentes pobres ainda continuam a ocupar um não-lugar social que só se torna visível pela "ameaça" ou pelo "risco" provocados na sociedade.

As ações que nascem em outras esferas e se autodenominam como políticas de juventude tentam constituir um novo discurso e, certamente, buscam construir acepções capazes de propor uma maior positividade na imagem dos segmentos juvenis, mas restam dissociadas das práticas destinadas aos "vulneráveis". No interior dessa dissociação, alguns caminhos podem ser observados em algumas cidades para estabelecer possíveis pontes: um deles reside na gradativa absorção pelas políticas de juventude das temáticas relativas aos adolescentes em processos de exclusão, constituindo outras imagens sociais, capazes de romper com o estigma dominante; o outro se identifica nos setores mais progressistas, que coordenam programas voltados para adolescentes na área da inserção ou assistência social que tendem a tornar mais complexa sua percepção das demandas desses sujeitos, diferenciado-as das práticas das crianças, observando-se uma aproximação em relação aos atores que estão na luta pelas políticas de juventude. Nesse caso trata-se de não inscrever esses adolescentes apenas no âmbito da questão social, mas em um conjunto diversificado de direitos comuns a todos os jovens da sociedade brasileira. Busca-se, assim, constituir um dissenso capaz de produzir uma outra imagem social, inevitavelmente normativa, dos sujeitos - jovens e adolescentes - aos quais se destinam suas ações.

Os esforços emergentes ainda não configuram organicidade e coerência de pressupostos no âmbito do mesmo Executivo municipal, que, no seu interior, produz, assim, práticas e discursos muitas vezes conflitantes.
Do mesmo modo, a participação e a democratização das ações do ponto de vista sociopolítico ainda são metas a serem atingidas. As iniciativas não configuram um quadro forte de orientações que criem na interação dos jovens com o governo local mecanismos plurais de participação que fortaleçam a constituição de espaços públicos democráticos. No entanto, nas ações em que esses pressupostos, embora minoritários no amplo espectro investigado, estão presentes, observa-se um efetivo espaço de interlocução com coletivos juvenis que tende a ser promissor. De modo geral, o novo ainda permanece, em grande parte, submerso, adquirindo visibilidade somente em iniciativas pontuais, frágeis e muitas vezes descontínuas.

\section{Referências bibliográficas}

BENARROCH, Yolande. Pour ou contre un revenu minimum inconditionnel. In: SEMINAIRE DE RECHERCHE POUR LES PERSONNELS ET ADMINISTRATEURS DE L'ASSOCIATION VERS LA VIE POUR L'ÉDUCATION DE JEUNES, 1998, Paris. Anais... Paris: [s.ed.], set. 1998 (mimeo).

BRASIL. Ministério do Desenvolvimento Social e Combate à Fome. Projeto Agente Jovem de Desenvolvimento Social e Humano. Brasília: Ministério de Desenvolvimento Social, 2004. Disponível em: <www.mds.gov.br>. Acesso em: 10 de abril de 2005.

BRASIL. Ministério da Previdência e Assistência Social. Guia de capacitação. Brasília: Núcleo Básico do Projeto Agente Jovem de Desenvolvimento Social e Humano, [s.d.].

Guia de Gestores do Programa Agente Jovem de Desenvolvimento Social e Humano. Brasília: Ministério da Previdência e Assistência Social, 2001a.

Projeto Agente Jovem de Desenvolvimento Social e

Humano. Brasília: Ministério da Previdência e Assistência Social, $2001 \mathrm{~b}$.

BRASIL. Tribunal de Contas da União. Avaliação do TCU sobre o Projeto Agente Jovem. Brasília: Tribunal de Contas da União, Secretaria de Fiscalização e Avaliação de Governo, 2004.

CAMACHO, Luiza. Projeto Agente Jovem: ação, programa ou política pública de juventude? In: REUNIÃO ANUAL DAANPEd, 27., 2004, Caxambu. Anais... Caxambu: ANPEd, 2004. 1 CD-ROM. CASTRO, Mary Garcia. O que dizem as pesquisas da UNESCO sobre juventudes no Brasil: leituras singulares. In: NOVAES, Regina 
Reyes; PORTO, Marta; HENRIQUES, Ricardo (Orgs.). Juventude, cultura e cidadania. Rio de Janeiro: Comunicações do Instituto de Estudos da Religião, 2002. p. 63-90 (Edição Especial).

CORTI, Ana Paula; SOUZA, Raquel. Diálogos com o mundo juvenil: subsídios para educadores. São Paulo: Ação Educativa, 2005. DRAIBE, Sonia. Reforma do Estado e descentralização: a experiência recente da política brasileira de ensino fundamental. In: INTERNATIONAL SEMINAR "RESTRYCTHYRUBG ABD GOVERNMENT REFORM: BRAZIL AND LATIN AMERICA IN A GLOBALIZATION CONTEXT”, 1998. [S.1.]: [s.ed.], maio 1998 (mimeo).

ELIAS, Norbert; DUNNING, Elias. Deporte y ócio en el proceso de la civilizacion. 2. ed. México: Fondo de Cultura Econômica, 1995. FERRETI, Celso; ZIBAS, Dagmar; TARTUCE, Gisela. Protagonismo juvenil na literatura especializada e na reforma do ensino médio. Cadernos de Pesquisa, v. 34, n. 122, p. 411-423, maio/ago. 2004. IBGE - Instituto Brasileiro de Geografia e Estatística. Censo de População 2000. Rio de Janeiro: Fundação Instituto Brasileiro de Geografia e Estatística, 2000.

LAGREE, Jean Charles. Age, jeunesse et politiques publiques. Paris: [s.ed.], 1999 (mimeo).

LEÃO, Geraldo. A gestão da pobreza juvenil: uma análise de um programa federal de inclusão social para jovens pobres. In: REUNIÃO ANUAL DA ANPEd, 27., 2004, Caxambu. Anais... Caxambu: ANPEd, 2004. 1 CD-ROM.

LONCLE-MORICEAU, Patrícia. La jeunesse: ambivalences et ambiguités autour d'une catégorie d'intervention publique. In: VULBEAU, Alain (Dir.). La jeneusse comme ressource. Toulouse: Érès, 2001. p. 79-94.

MARTINS, Carlos Henrique dos Santos. Políticas públicas de esportes para juventude na Baixada Fluminense: uma discussão introdutória. In: REUNIÃO ANUAL DA ANPEd, 27., 2004, Caxambu. Anais... Caxambu: ANPEd, 2004. 1 CD-ROM.

MARTINS, José de Souza. Exclusão social e a nova desigualdade. São Paulo: Paulus, 1997.

PEREIRA, Luís Carlos Bresser; WILHEIM, Jorge; SOLA, Lourdes. Sociedade e Estado em transformação. São Paulo: UNESP/Imprensa Oficial/ENAP, 1999.

RANCIÈRE, Jacques. O desentendimento. São Paulo: Editora 34, 1996. RUA, Maria das Graças. As políticas públicas e a juventude dos anos 90. In: CNPD. Jovens acontecendo na trilha das políticas públicas. Brasília: CNPD, 1998, v. 2. p. 731-752.

SALES, Mione. (In)visibilidade perversa: adolescentes infratores como metáfora da violência. 2005. Tese (Doutorado em Sociolo- gia) - Faculdade de Filosofia, Letras e Ciências Humanas, Universidade de São Paulo, São Paulo, 2005.

SOLA, Lourdes. Juventude, comunidade política e sociedade civil. In: CNPD. Jovens acontecendo na trilha das politicas públicas. Brasília: CNPD, 1998, v. 2. p. 753-768.

SPOSITO, Marilia Pontes. Trajetórias na constituição de políticas públicas de juventude no Brasil. In: FREITAS, Maria Virginia; PAPA, Fernanda de Carvalho (Orgs.). Politicas públicas de juventude. Juventude em pauta. São Paulo: Cortez/Ação Educativa/Fundação Friedrich Ebert Stiftung, 2003. p. 57-74.

. Algumas reflexões e muitas indagações sobre as relações entre juventude e escola no Brasil. In: ABRAMO, Helena; BRANCO, Pedro Paulo (Orgs.). Retratos da juventude brasileira. Análises de uma pesquisa nacional. São Paulo: Instituto da Cidadania/Editora Fundação Perseu Abramo, 2005. p. 129-148.

; CARRANO, Paulo César. Juventude e políticas públicas no Brasil. Revista Brasileira de Educação, Rio de Janeiro/Campinas: ANPEd/Autores Associados, n. 24, p. 16-39, set./dez. 2003. SPOSITO, Marilia Pontes; CORROCHANO, Maria Carla. A face oculta dos programas de transferência de renda para jovens no Brasil. Revista Tempo Social, USP, Departamento de Sociologia, v. 17, n. 2, p. 141-172, nov. 2005.

MARILIA PONTES SPOSITO é professora titular em sociologia da educação na Faculdade de Educação da Universidade de São Paulo (USP) e membro da diretoria de Ação Educativa. Principais publicações: $O$ povo vai à escola: a luta popular pela expansão do ensino público em São Paulo (São Paulo: Loyola, 1984); A ilusão fecunda: a luta por educação nos movimentos populares (São Paulo: Hucitec/EDUSP, 1993); O trabalhador-estudante: um perfil do aluno do curso superior noturno (São Paulo: Loyola, 1989, em colaboração). Coordenou a pesquisa e a publicação de Juventude e escolarização - 1980/1998 (Brasília: INEP/ MEC, 2003, Série Estado do Conhecimento, n. 7). Coordenou o projeto de pesquisa "Juventude, escolarização e poder local” (Conselho Nacional de Desenvolvimento Científico e Tecnológico CNPq, Fundação de Amparo à Pesquisa do Estado de São Paulo FAPESP) e coordena atualmente o projeto de pesquisa "Balanço e perspectivas do campo de estudos de juventude no Brasil em conjuntura de expansão", com apoio do CNPq.E-mail: sposito@usp.br

Recebido em dezembro de 2005 Aprovado em março de 2006 
res las fuentes de las dificultades particulares de la escuela y de la enseñanza en los barrios populares.

Palabras claves: socialización; modo de socialización escolar; socialización en familias de clases sociales populares; socialización y escolarización; relación escuela-familia

Nadir Zago

Do acesso à permanência no ensino superior: percursos de estudantes universitários de camadas populares O presente artigo trata da problemática das desigualdades educacionais, com longa tradição na sociologia da educação, e sobre a presença de estudantes de origem popular no ensino superior. O eixo central da análise contempla as desigualdades de acesso e de permanência no ensino superior. Os resultados apresentados estão apoiados em uma pesquisa, com duas fontes principais de informação: de natureza quantitativa, apoiada nas estatísticas dos candidatos inscritos no exame de acesso à universidade; em dados mais aprofundados, obtidos em entrevistas com 27 estudantes. A discussão do trabalho permite mostrar as contradições entre uma maior demanda da população pela elevação do nível escolar e as políticas de acesso e de permanência no sistema de ensino superior brasileiro.

Palavras-chave: ensino superior; desigualdades sociais e educacionais

From access to permanence in higher education: the trajectories of university students of popular origin This article deals with the problem of inequalities in education, a theme dear to the sociology of education, and of the presence of students of popular origin in higher education. The central axis of this analysis is that of the inequalities of access and permanence of those students in higher education.

The results are based on the conclusions of a research based on two main sources of information: 1) of a quantitative nature: the data on students enrolled in the university admission exam; 2) more qualitative data obtained from interviews with 27 students. This study permits us to show the contradictions between a greater demand for higher levels of education and the policies of access and permanence to the Brazilian system of higher education.

Key-words: higher education; social and educational inequalities

Del acceso a la pernanencia en la enseñanza superior : trayectos de estudiantes universitarios de clases sociales populares

El presente artículo trata de la problemática de las desigualdades educativas, con larga tradición en la sociología de la educación, y sobre la presencia de estudiantes de origen popular en la enseñanza superior. El eje central del análisis son las desigualdades de acceso y de permanencia en la enseñanza superior. Los resultados que fueron presentados están apoyados en una pesquisa, con dos principales fuentes de información: 1) de naturaleza cuantitativa, apoyada en las estadísticas de los candidatos inscriptos en el examen de acceso a la universidad; 2) en datos más profundos obtenidos en entrevistas con 27 estudiantes. La discusión del trabajo permite mostrar las contradicciones entre una mayor demanda de la populación, devido a la elevación del nivel escolar y las políticas de acceso y de permanencia en el sistema de la enseñanza superior brasileña.

Palabras claves: enseñanza superior; desigualdades sociales y educativas

Marilia Pontes Sposito, Hamilton Harley de Carvalho e Silva, Nilson Alves de Souza

Juventude e poder local: um balanço de iniciativas públicas voltadas para jovens em municípios de regiões metropolitanas

Reúne os resultados preliminares do projeto de pesquisa "Juventude, escolarização e poder local”, que examina iniciativas públicas desenvolvidas pelo Executivo municipal em 74 municípios de regiões metropolitanas do Brasil (Sudeste, Sul, Centro-Oeste e Nordeste) no período entre 2001 e 2004 . As principais ações são investigadas tendo como eixos analíticos o conjunto de percepções sobre juventude que ancoram as iniciativas e as formas que são propostas pelo poder público para a interação com os segmentos juvenis. Palavras-chave: juventude; políticas públicas; poder local

Youth and local power: a balance of public initiatives directed at young people in municipalities pertaining to metropolitan regions

Presents the preliminary results of the research project "Youth, schooling and local power" which examines public initiatives developed by municipal governments in 74 municipalities pertaining to metropolitan regions in Brazil (Southeast, South, Central West and Northeast) in the period between 2001 and 2004. The principal actions are investigated taking as analytic axes the set of perceptions on youth which anchor the initiatives and the forms which are proposed by the public power for interaction with this segment of the population.

Key-words: youth; public policy; local power

Juventud y poder local: un balance de iniciativas públicas dirigidas para jóvenes en municipios de regiones metropolitanas

Reune los resultados preliminares del proyecto de investigación "Juventud, escolarización y poder local" que examina iniciativas públicas desarrolladas por el ejecutivo municipal en 74 municipios de regiones metropolitanas 
de Brasil (Sudeste, Sur, Centroeste y

Noreste) en el período 2001-2004. Las principales acciones son investigadas teniendo como ejes analíticos el conjunto de percepciones sobre juventud que anclan las iniciativas y las formas que son propuestas por el Poder Público para la interacción con los segmentos juveniles.

Palabras claves: juventud; políticas públicas; poder local

Maria Isabel da Cunha

Docência na universidade, cultura e avaliação institucional: saberes silenciados em questão

Apresenta os resultados de pesquisa interinstitucional sobre o Exame Nacional de Cursos, conhecido como "provão", na qual foram entrevistados alunos, coordenadores e professores de doze cursos de graduação, pertencentes a instituições de ensino superior do estado do Rio Grande do Sul. Os resultados detectaram elementos de impacto das políticas avaliativas sobre as formas de atuação dos professores. Houve, entretanto, variação de resultados, de acordo com a natureza dos cursos. Nos cursos que preparam para profissões liberais a lógica concorrencial foi mais presente e nas licenciaturas houve uma centralidade nos processos pedagógicos. Ambos, entretanto, foram atingidos nas suas subjetividades e tendem a reorganizar suas práticas segundo o parâmetro de sucesso imposto pelo modelo avaliativo. Interferem nos saberes docentes, silenciando muitos daqueles que se contrapõem ao padrão imposto pela avaliação, direcionando a qualidade da prática pedagógica universitária.

Palavras-chave: políticas de avaliação; pedagogia universitária; saberes docentes

Teaching in higher education, culture and institutional evaluation: the matter of silenced knowledge
The paper reports results from an interinstitutional research on the Brazilian National Course Exam. Students, teachers and coordinators belonging to 12 higher education courses from different institutions at the state of Rio Grande do Sul were interviewed. Results detected the impact of evaluation policies on the performance of teachers. There were, nevertheless, some variety among the results, when different courses were concerned. Courses focusing on liberal professions showed a competitive approach while those focusing on teacher training programmes were more centered on pedagogical processes. Nonetheless, both profiles were hit on their subjectivity and showed a tendency to reorganization towards the success parameters imposed by the evaluation model. The model interferes with teachers knowledge and silences many of those contra posing the patterns imposed by the evaluation, directing the quality of pedagogical practice at the universities.

Key-words: evaluation policies; pedagogical university; knowledge teachers

Docencia en la universidad, cultura y validez institucional: saberes silenciados en cuestión

Presenta los resultados de encuesta interinstitucional sobre el Examen $\mathrm{Na}$ cional de Cursos, conocido como "provão", en la cual fueron entrevistados alunos, coordenadores y profesores de doce cursos de graduación pertenecientes a instituciones de enseñanza superior del estado de Rio Grande del Sur. Los resultados detectaron elementos de impacto de las políticas evaluativas sobre las formas de actuación de los profesores. Hubo, entretanto, variación de resultados, de acuerdo con la naturaleza de los cursos. En los cursos que preparan para profesiones liberales la lógica concurrencia fue más presente y en las licenciaturas hubo una centralidad en los procesos pedagógicos. Ambos, entre tanto, fueron alcanzados en sus objetividades y tienden a reorganizar sus prácticas según el parámetro de suceso impuesto por el modelo evaluativo. Interfieren en los saberes docentes, silenciando muchos de aquellos que se contraponen al padrón impuesto por la evaluación, direccionando la cualidad de la práctica pedagógica universitaria.

Palabras claves: politicas de evaluación; pedagogía universitaria; saberes docentes

Danilo R. Streck

A educação popular e a (re)construção do público. Há fogo sob as brasas?

O artigo busca situar a educação popular no contexto da reconstrução da esfera pública na América Latina. A partir da volta às suas origens para identificar o lugar social e os espaços pedagógicos nos quais a educação popular se originou, argumenta que um traço distintivo dela é a própria busca, no mesmo sentido em que a identidade latino-americana se constitui como esse lugar de possibilidades. Analisa a seguir algumas estratégias pedagógicas clandestinas, assim entendidas por se caracterizarem como ausência ou ocultamento, respectivamente: pedagogia da sobrevivência, da resistência e da relação. No final, retorna à imagem do labirinto para definir as perplexidades - históricas e atuais - da educação popular.

Palavras-chave: educação popular; América Latina; esfera pública; pedagogias alternativas

\section{Popular education and the} (re)construction of the public sphere. Is there fire in the embers?

The main purpose of this article is to situate popular education within the 